\title{
Magnitude and Risk of Dying among Low Birth Weight Neonates in Rural Ethiopia: A Community-Based Cross-Sectional Study
}

\author{
Akine Eshete $\mathbb{D}^{1},{ }^{1}$ Abebe Alemu $(\mathbb{D})^{2}$ and Taddes Alemu Zerfu $\mathbb{D}^{3}$ \\ ${ }^{1}$ College of Health Sciences and Medicine, Department of Public Health, Debre Berhan University, Ethiopia \\ ${ }^{2}$ College of Health Sciences and Medicine, Department of Midwifery, Dilla University, Dilla, Ethiopia \\ ${ }^{3}$ College of Health Sciences and Medicine, Department of Public Health, Dilla University, Dilla, Ethiopia \\ Correspondence should be addressed to Akine Eshete; akine.eshete@yahoo.com
}

Received 5 December 2018; Revised 25 March 2019; Accepted 14 April 2019; Published 16 May 2019

Academic Editor: Samuel Menahem

Copyright (C) 2019 Akine Eshete et al. This is an open access article distributed under the Creative Commons Attribution License, which permits unrestricted use, distribution, and reproduction in any medium, provided the original work is properly cited.

\begin{abstract}
Background. Even if remarkable progress has been made in reducing preventable child deaths worldwide, neonatal mortality reduction has remained unsatisfactory. Low birth weight (LBW) is the major risk factor for child deaths during the neonatal period, yet only $5 \%$ of babies are weighed at birth in Ethiopia. The aim of the present study was to determine the magnitude and risk of dying among low birth weight neonates in rural Gedeo, Southern Ethiopia. Methods. Community-based mixed-method approach design was employed between September and October 2016 to identify and enroll study participants in rural Gedeo, Southern Ethiopia. Records of 17,503 live birth babies, of whom 2,065 (11.8\%) had LBW, born in the last 12 months were screened to identify $885(42.8 \%)$ biological mother-LBW neonate pairs from eight health centers. The study subjects were randomly selected using a multistage stratified cluster sampling technique. Cox proportional hazards regression model was used to predict maternal and neonatal risk factors associated with the risk of neonatal death. Results. The overall neonatal mortality rate (NMR) among LBW infants was 110 per 1000 live births (95\% confidence interval: 75 -228). Close to half, 374 (42.3\%), of the LBW neonates died during the first week of life. The estimated hazard ratios of mortality were higher among neonates whose mothers did not attend antenatal care (ANC) $(\mathrm{HR}=1.58,95 \% \mathrm{CI}: 1.02-2.43)$, gave birth by assisted or cesarean delivery (HR=1.81 and 3.72; $95 \%$ CI: $1.10-3.02$ and 2.11-6.55), and experienced some form of illness during pregnancy ( $\mathrm{HH}=3.34,95 \% \mathrm{CI}$ : 2.11-5.29), respectively. Similarly, neonates born with very low $(<2000 \mathrm{gm})$ birth weight and born prematurely (before 37 weeks of gestation) carried a higher $(\mathrm{HR}=1.90$ and 1.47; 95 \% CI: 1.22 - 2.96 and 1.07-2.28) risk of death. On the other hand, maternal formal education was found to be the single protective factor ( $\mathrm{HR}=0.65,95 \% \mathrm{CI}$ : 0.43-0.99). Conclusion. Nearly one in every ten (11\%) of neonates die before celebrating their firth month of life, mainly during the first week in rural Ethiopia. The risk of dying from LBW during the neonatal period is almost fourfold of the current estimated national NMR. Maternal obstetric characteristics and fetal maturity were predictors of mortality.
\end{abstract}

\section{Introduction}

Though remarkable progress has been made in averting preventable child deaths, the neonatal mortality rate remains too high [1-3]. Promisingly, the leading causes for the vast majority of under-five deaths are infectious diseases and neonatal complications that could be readily preventable or treatable with proven, cost-effective, and quality delivered interventions [3-5]. Several studies from low- and middleincome countries [6-9] reported that neonatal death was associated with factors that could be easily implemented through the provision of a continuum of care from pregnancy to delivery and to the immediate postnatal period.

Low birth weight (LBW) is one of the key drivers and indirect causes of neonatal death [10]. It contributes to $60 \%$ to $80 \%$ of all neonatal deaths, annually [11]. A baby born with LBW is at a higher risk of morbidity [12], inhibited growth [13], poor cognitive development [11, 14], remaining underweight and stunted in early childhood [15], growing into shorter adults, and developing chronic diseases at later ages of life [16]. Low birth weight girls tend to grow into women with short stature and an underdeveloped pelvis, 
leading to obstetric complications during childhood [17]. According to recent estimates, each year, more than 20 million infants across the globe representing 15 to 20 percent of all life born babies have low birth weight (LBW) [13].

However, little is known about community-level factors associated with the risk progress made to reduce LBW and the associated neonatal mortality, in spite of ample evidence relating to prevention of LBW using low cost, simple, and proven technologies/interventions $[13,18]$. A recent report from the lancet showed that avoiding any barrier at the time of birth could save an estimated 1.3 million newborn deaths annually by 2020 [4].

In Ethiopia, the latest (2015/16) estimate of neonatal mortality rate is 28 per 1000 live births and accounts for about half $(47.5 \%)$ of the overall child mortality rate $[3,19]$. The risk of neonatal death in the country varies in terms of sociodemographic and economic factors such as region, place of residence, geographic location, maternal educational status, and family wealth index [20,21]. For example, in some regions of the country like Benishangul, Afar, Gambella, Somali, and Southern Nations, Nationalities, and People's Region, the NMR is incomparably high. Furthermore, children from rural, poor/poorest, uneducated, or less educated family (mother) carry a disproportionally higher risk of neonatal mortality [21-23].

The critical challenge of programs and interventions in Ethiopia remains to be a paucity of comprehensive community-based evidence as many of the neonatal deaths happen at home (not more than $5 \%$ of babies are weighted at birth) and left undetected [22]. Moreover, few of the available studies are often facility-based or investigated neonatal mortality as a whole, not inferring LBW babies in particular. To the best of our knowledge, this is the first community-based study investigating the burden and predictors of mortality among LBW neonates.

Therefore, the present study aimed to generate and analyze community-based data on the magnitude and associated maternal and neonatal risk factors of neonatal death among LBW neonates in rural communities of Gedeo zone, Southern Ethiopia. The study findings will be used as inputs for policy makers and program implementers to design and implement context-based intervention to tackle the problem.

\section{Methods and Materials}

We employed a community-based cross-sectional quantitative study design to collect data on magnitude and LBW related death risks between September and October 2016. The study was conducted in three randomly selected districts of the Gedeo zone in the Southern Nations, Nationalities, and People's (SNNP) Regional State of Ethiopia. The zone has six districts and two administrative towns (namely, Dilla and Yirgachefe towns) and is known for leading coffee producing areas in the country. We selected three districts and six clusters or kebeles (smallest administrative units) for the study.

2.1. Ethics Statement. The study was approved by the Health Research and Ethics Review Committee of the College of
Health Sciences of Dilla University. Written informed consent was obtained from the participants. The information obtained was kept anonymous, thereby ensuring confidentiality.

2.2. Recruitment and Interviewing of Study Participants. The study population comprises pairs of mothers and LBW infants born alive 12 months prior to the data collection period. The infants were included only when they were living with their biological mothers, having birth certificates, apparently healthy, and born with a birth weight of $<2500 \mathrm{gm}$.

A multistage cluster sampling technique was employed to select and enroll mothers in the study. The stratification was into urban and rural strata, followed by the use of simple random sampling to identify three districts and study clusters (kebeles). A total of six clusters (two from each district) were randomly selected and included to the study. Form the selected clusters, all neonates were included in the study; this yielded a total sample of 885 mother-LBW neonate pairs.

Data were collected with face to face interview questionnaires. The questionnaires were designed and modified in comparison with previous studies $[6,8]$. Data were collected by twelve health extension workers and four supervisors after three days of intensive training on interviewing techniques and measurements. Completed questionnaires were reviewed daily by the supervisors and principal investigators.

The dependent variable, neonatal death, was determined by recording the death of neonates within the first 28 days in the surveyed households and predicting variables from maternal and neonatal risk factors for neonatal death. Neonatal death is defined as death before 28 completed days. The date of death was recorded and infants who lived beyond 28 days were also censored at the time of data collection in completing of survival analysis.

2.3. Data Management and Analysis. Data were entered using Epi INFO vision 3.5.1 and exported to SPSS V-20 for analysis. Cox proportional hazards model was used to investigate maternal and neonatal risk factors for neonatal death. Explanatory variables with a $p<0.20$ in univariate Cox-regression analysis were further included in the multiple-Cox-regression analysis. Finally, the multiple-Coxregression analysis was used to estimate hazard ratios (HR); corresponding with its $95 \%$ confidence intervals (CI).

\section{Results}

3.1. Characteristics of Mothers and Neonates. Overall, 885 mother-neonate pairs were included in the study. Nearly half, 380 (43\%), of mothers were $24-29$ years old with a mean $( \pm$ SD) and a median age of $28.5( \pm 4.8)$ and 28.0 years, respectively. More than half, 518 (58.5\%), of mothers did not attend formal education and $75.5 \%$ were housewives. Even though most, 688 (77.7\%), of mothers reported to have at least one antenatal care (ANC) visit during their last pregnancy, less than one-fifth, 126(18.3\%), had four or more ANC visits. The proportion of twin births was $4.4 \%$ (Table 1). 
TABLE 1: Selected sociodemographic and reproductive characteristics of mothers and neonates, rural Gedeo, Southern Ethiopia, 2016.

\begin{tabular}{|c|c|}
\hline Variables & Number $(\%)^{\mathrm{n}}$ \\
\hline \multicolumn{2}{|l|}{ Age of mother at last birth } \\
\hline$\leq 24$ Years & $177(20.0)$ \\
\hline 24-29 Years & $380(42.9)$ \\
\hline$\geq 30$ & $328(37.1)$ \\
\hline \multicolumn{2}{|l|}{ Ethnicity group } \\
\hline Gedeo & $793(89.5)$ \\
\hline Others & $93(10.5)$ \\
\hline \multicolumn{2}{|l|}{ Educational status of mother } \\
\hline Uneducated & $518(58.5)$ \\
\hline Educated & $367(41.5)$ \\
\hline \multicolumn{2}{|l|}{ Occupational status of mother } \\
\hline House wife & $668(75.5)$ \\
\hline Employed (Self, Government and Private) & $217(24.5)$ \\
\hline \multicolumn{2}{|l|}{ Sex of Neonate } \\
\hline Male & $431(48.7)$ \\
\hline Female & $454(51.3)$ \\
\hline \multicolumn{2}{|l|}{ Types of Birth } \\
\hline Singleton & $846(95.6)$ \\
\hline Twins & $39(4.4)$ \\
\hline \multicolumn{2}{|l|}{ ANC Follow-Up } \\
\hline Yes & $688(77.7)$ \\
\hline No & $197(22.3)$ \\
\hline \multicolumn{2}{|l|}{ Number of ANC Visits } \\
\hline$<4$ Visits & $562(81.7)$ \\
\hline $4^{+}$Visits & $126(18.3)$ \\
\hline
\end{tabular}

TABLE 2: Timing of neonatal death among infants of low birth weight in rural districts of Gedeo, Southern Ethiopia, 2016.

\begin{tabular}{lcc}
\hline Events & Death (n) & $95 \%$ CI \\
\hline Neonatal deaths in $1^{\text {st }}$ week & 41 & $42.3(33.0-51.5)$ \\
Neonatal deaths in $2^{\text {nd }}$ week & 25 & $25.8(17.5-35.1)$ \\
Neonatal deaths in $3^{\text {rd }}$ week & 24 & $24.7(16.5-33.0)$ \\
Neonatal deaths in $4^{\text {th }}$ week & 7 & $7.2(2.1-13.4)$ \\
Early neonatal death & 43 & $42.3(32.1-52.6)$ \\
Late neonatal death & 56 & $57.7(47.4-67.9)$ \\
Total neonatal deaths & 97 & $11.0(8.8-13.1)$ \\
\hline
\end{tabular}

3.2. Magnitude and Timing of Death among LBW Neonates. From the total $885 \mathrm{LBW}$ neonates born during the study period, over one in every ten 97 (10.9\%), 95\% confidence interval (CI), 8.8-13.1) died before completing 28 days of life. A higher number of deaths were recorded during the first $41(4.6 \%)$, second $25(2.8 \%)$, and third 24 (2.7\%) weeks of neonatal life (Table 2).

3.3. Neonatal Death and Maternal Characteristics. A higher proportion of neonatal death was observed among mothers aged >30yrs, 46 (47.7\%); married, 85 (87.6\%); being unemployed/housewives, 61 (62.9\%); attending fewer $(<4)$
ANC visits, 47 (83.9\%); having spontaneous vaginal delivery, 44 (45.4\%); and experiencing some form of illness during pregnancy, 58 (59.8\%) (Table 3). Similarly, neonates who had very low $(<2000 \mathrm{gm})$ birth weight and twins also had a higher risk of death (Table 4$)$.

3.4. Risk Factors for Neonatal Death among Low Birth Weight Babies. A proportional Cox-regression analysis was employed to examine maternal and newborn factors affecting neonatal death, and results are presented in Tables 5 and 6. In binary Cox-regression analysis, neonates whose mothers did not have ANC follow-up visit ( $\mathrm{HR}=2.67,95 \% \mathrm{CI}: 1.78$ -3.98), were grand multiparous (have more than six birth) $(\mathrm{HR}=2.19,95 \%$; CI: 1.28, 3.74), and had maternal illness during perinatal period ( $\mathrm{HR}=5.28,95 \%$; $\mathrm{CI}: 3.52,7.93)$ carried a high risk of neonatal death. In addition, mothers who had either instrumental or cesarean delivery carried a three- to sevenfold $(\mathrm{HR}=3.36$ and $7.44 ; 95 \% \mathrm{CI}: 2.12,5.35$ and 4.4912.32) higher risk of neonatal death compared to mothers who had a spontaneous vaginal delivery (SVD) (Table 5). Neonates born before 37 weeks of gestation, in multiple births, and with birth weight $<2000 \mathrm{gm}$ had a $1.81(\mathrm{HR}=1.81,95 \% \mathrm{CI}$ : 1.19-2.75), $3.07(\mathrm{HR}=3.07,95 \% \mathrm{CI}: 1.66-5.75)$, and $3.08(\mathrm{HR}=$ $3.08,95 \%$ CI: 2.07-4.60) higher risk of death.

During the multivariate-adjusted hazard analysis, maternal education ( $\mathrm{HR}=0.65,95 \% \mathrm{CI}$ : 0.43-0.99), instrumental $(\mathrm{HR}=1.81,95 \% \mathrm{CI}: 1.10-3.02)$ or cesarean delivery $(\mathrm{HR}=3.72$, $95 \%$ CI: 2.11- 6.55), lack of ANC follow-up visits $(\mathrm{HR}=1.58$, $95 \%$ CI: 1.02-2.43), and experiencing some form of illness during pregnancy $(\mathrm{HR}=3.34,95 \% \mathrm{CI}$ : 2.11-5.29) remained as independent maternal risk factors predicting higher risk of death among LBW neonates (Table 5).

In the same way, prematurity $(\mathrm{HR}=1.47,95 \% \mathrm{CI}: 1.07-$ 2.28) and very low birth weight at birth $(\mathrm{HR}=1.90,95 \%$ CI: 1.22-2.96) were neonatal conditions with independent predictors of higher risk of mortality of LBW infants.

\section{Discussion}

In this paper, we described the results of a community-based cross-sectional study that aimed to determine the magnitude and predictors of death among LBW neonates in rural districts of Gedeo, Southern Ethiopia. We found that nearly one in every ten (11\%) (95\% CI: 17.5 - 22.8) LBW infants were dying before celebrating their first month of life (neonatal period). We observed that the risk of death was much higher during the first week of life. Both maternal and neonatal factors were significantly associated with the risk of death of an LBW neonate. Maternal obstetric characteristics like too few or no ANC follow-up visits, assisted/caesarian delivery, and experience of some form of illness during pregnancy and neonatal birth conditions like prematurity and having very low birth weight at birth were independent predictors of mortality among LBW neonates.

The magnitude of neonatal death (110 per 1000 LB) observed among LBW neonates in the current study is almost a fourfold of the overall estimated national neonatal mortality rate (28 per $1000 \mathrm{LB}$ ) for Ethiopia [3] and exceeds the rate for similar middle-income city, Cuiaba, of Brazil by 63.6\% [24]. 
TABle 3: Distribution of neonatal deaths described by maternal sociodemographic and obstetric characteristics, rural Gedeo, Southern Ethiopia, 2016.

\begin{tabular}{|c|c|c|}
\hline Variables & Total N (\%) & Death N (\%) \\
\hline \multicolumn{3}{|l|}{ Age } \\
\hline$\leq 24$ years & $177(20.0)$ & $14(14.4)$ \\
\hline $24-29$ years & $380(42.9)$ & $37(38.1)$ \\
\hline$\geq 30$ & $328(37.1)$ & $46(47.7)$ \\
\hline \multicolumn{3}{|l|}{ Educational status } \\
\hline No formal education & $518(58.5)$ & $49(50.5)$ \\
\hline Formal education & $367(41.5)$ & $48(49.5)$ \\
\hline \multicolumn{3}{|l|}{ Marital status } \\
\hline Married & $827(93.4)$ & $85(87.6)$ \\
\hline Other & $58(6.6)$ & $12(12.4)$ \\
\hline \multicolumn{3}{|l|}{ Occupational } \\
\hline House wife & $668(75.5)$ & $61(62.9)$ \\
\hline Employed & $217(24.5)$ & $36(37.1)$ \\
\hline \multicolumn{3}{|l|}{ ANC follow up } \\
\hline Yes & $688(77.7)$ & $56(57.7)$ \\
\hline No & $197(22.3)$ & $41(42.3)$ \\
\hline \multicolumn{3}{|c|}{ Number of ANC visits $(n=688)$} \\
\hline$<4$ ANC visits & $562(81.7)$ & $47(83.9)$ \\
\hline$\geq 4$ ANC visits & $126(18.3)$ & $9(16.1)$ \\
\hline \multicolumn{3}{|l|}{ Mode of delivery } \\
\hline Vaginal delivery & $681(76.9)$ & $44(45.4)$ \\
\hline Assisted delivery & $148(16.7)$ & $30(30.9)$ \\
\hline Cesarean section & $56(6.3)$ & $23(23.7)$ \\
\hline \multicolumn{3}{|l|}{ Illness during pregnancy } \\
\hline Yes & $214(24.2)$ & $58(59.8)$ \\
\hline No & $671(75.8)$ & $39(40.2)$ \\
\hline
\end{tabular}

TABle 4: Distribution of neonatal deaths described by neonatal birth characteristics, rural Gedeo, Southern Ethiopia, 2016.

\begin{tabular}{|c|c|c|}
\hline Variables & Total N (\%) & Death N (\%) \\
\hline \multicolumn{3}{|c|}{ Preceding birth interval (year) } \\
\hline First birth & $125(14.1)$ & $10(10.3)$ \\
\hline$<2$ years & $327(36.9)$ & $40(41.2)$ \\
\hline$>3$ years & $433(48.9)$ & $47(48.5)$ \\
\hline \multicolumn{3}{|l|}{ Birth order } \\
\hline$<2$ nd birth & $324(36.6)$ & $26(26.8)$ \\
\hline 3rd-5th birth & $404(45.6)$ & $44(45.4)$ \\
\hline$>6$ th birth & $157(17.7)$ & $27(27.8)$ \\
\hline \multicolumn{3}{|l|}{ Sex of neonate } \\
\hline Male & $431(48.7)$ & $49(50.5)$ \\
\hline Female & $451(51.3)$ & $48(49.5)$ \\
\hline \multicolumn{3}{|l|}{ Types of birth } \\
\hline Singleton & $846(95.6)$ & $86(88.8)$ \\
\hline Twins & $39(4.4)$ & $11(11.3)$ \\
\hline \multicolumn{3}{|l|}{ Weight of neonates } \\
\hline$<2000$ grams & $195(22.0)$ & $44(45.4)$ \\
\hline$>2000$ grams & $690(78.0)$ & $53(54.6)$ \\
\hline \multicolumn{3}{|l|}{ Gestation age at birth } \\
\hline Preterm $(<37$ weeks & $201(22.7)$ & $33(34.0)$ \\
\hline Term (>37 weeks) & $684(77.3)$ & $64(66.0)$ \\
\hline
\end{tabular}


TABle 5: Proportional Cox-regression analysis of maternal risk factors associated with neonatal death in rural districts of Gedeo Zone, Southern Ethiopia, 2016.

\begin{tabular}{|c|c|c|c|c|c|c|}
\hline \multirow{2}{*}{ Variables } & \multirow{2}{*}{ Total $(\mathrm{n}=885)$} & \multirow{2}{*}{ Death $n=97(n=\%)$} & \multicolumn{2}{|c|}{ Crude HR } & \multicolumn{2}{|c|}{ Adjusted HR } \\
\hline & & & $95 \%$ CI & $\mathrm{P}$-values & $95 \% \mathrm{CI}$ & $\mathrm{P}$-values \\
\hline \multicolumn{7}{|l|}{ Maternal age at birth } \\
\hline$\leq 24$ years & 177 & $14(7.9)$ & $0.80(0.43-1.48)$ & 0.473 & $0.81(0.41-1.63)$ & 0.555 \\
\hline $24-29$ years & 380 & $37(9.7)$ & 1(Ref) & & 1 (Ref) & \\
\hline$\geq 30$ & 328 & $46(14.0)$ & $1.44(0.94-2.23)$ & 0.094 & $1.05(0.62-1.81)$ & 0.848 \\
\hline \multicolumn{7}{|l|}{ Educational status } \\
\hline Non educated & 518 & $49(9.5)$ & 1(Ref) & & 1 (Ref) & \\
\hline Educated & 367 & $48(13.1)$ & $0.71(0.48-1.06)$ & 0.091 & $0.65(0.43-0.99)$ & 0.049 \\
\hline \multicolumn{7}{|l|}{ ANC follow-up } \\
\hline Yes & 688 & $56(8.1)$ & $1(\operatorname{Ref})$ & & $1(\operatorname{Ref})$ & \\
\hline No & 197 & $41(20.8)$ & $2.67(1.78-3.98)$ & $<0.001$ & $1.58(1.02-2.43)$ & 0.040 \\
\hline \multicolumn{7}{|l|}{ Mode of delivery } \\
\hline Vaginal delivery & 681 & $44(6.5)$ & $1(\operatorname{Ref})$ & & $1(\operatorname{Ref})$ & \\
\hline Assisted delivery & 148 & $30(20.3)$ & $3.36(2.12-5.35)$ & $<0.001$ & $1.82(1.10-3.02)$ & 0.020 \\
\hline Cesarean section & 56 & $23(41.1)$ & $7.44(4.49-12.32)$ & $<0.001$ & $3.72(2.11-6.55)$ & 0.001 \\
\hline \multicolumn{7}{|c|}{ Maternal illness during perinatal } \\
\hline Yes & 214 & $58(27.1)$ & $5.28(3.52-7.93)$ & $<0.001$ & $3.34(2.11-5.29)$ & 0.001 \\
\hline No & 671 & $39(5.8)$ & $1(\operatorname{Ref})$ & & $1(\operatorname{Ref})$ & \\
\hline
\end{tabular}

TABLE 6: Proportional Cox-regression analysis of newborn related risk factors associated with death, rural Gedeo Zone, Southern Ethiopia, 2016.

\begin{tabular}{|c|c|c|c|c|c|c|}
\hline \multirow{2}{*}{ Variables } & \multirow{2}{*}{$\begin{array}{c}\text { Total } \\
(\mathrm{n}=885)\end{array}$} & \multirow{2}{*}{$\begin{array}{c}\text { Death }^{1} \\
(\mathrm{n} / \%)\end{array}$} & \multicolumn{2}{|c|}{ Crude HR } & \multicolumn{2}{|c|}{ Adjusted HR } \\
\hline & & & $95 \% \mathrm{CI}$ & $\mathrm{P}$-values & $95 \%$ CI & P-values \\
\hline \multicolumn{7}{|l|}{ Birth interval (year) } \\
\hline First birth & 125 & $10(8.0)$ & $0.73(0.38-1.45)$ & 0.367 & & \\
\hline$<2$ years & 327 & $40(12.2)$ & $1.12(0.74-1.71)$ & 0.590 & & \\
\hline$>3$ years & 433 & 47 (10.9) & $1($ Ref $)$ & & & \\
\hline \multicolumn{7}{|l|}{ Birth order } \\
\hline$<2$ nd birth & 324 & $26(8.0)$ & $0.72(0.44-1.17)$ & 0.187 & $1.28(0.70-2.33)$ & 0.425 \\
\hline 3rd-5th birth & 404 & $44(10.9)$ & $1(\operatorname{Ref})$ & & $1(\operatorname{Ref})$ & \\
\hline$>6$ th birth & 157 & $27(17.2)$ & $1.58(0.98-2.55)$ & 0.063 & $1.04(0.59-1.83)$ & 0.900 \\
\hline \multicolumn{7}{|l|}{ Sex } \\
\hline Male & 431 & 49 (11.4) & $1.09(0.73-1.61)$ & 0.700 & & \\
\hline Female & 454 & $48(10.6)$ & $1(\operatorname{Ref})$ & & & \\
\hline \multicolumn{7}{|l|}{ Types of birth } \\
\hline Singleton & 846 & $86(10.2)$ & $1(\operatorname{Ref})$ & & $1(\operatorname{Ref})$ & \\
\hline Twins & 39 & $11(28.2)$ & $3.07(1.64-5.75)$ & $<0.001$ & $1.49(0.77-2.91)$ & 0.239 \\
\hline \multicolumn{7}{|l|}{ Weight of neonates } \\
\hline$<2000$ grams & 195 & $44(22.6)$ & $3.08(2.07-4.60)$ & $<0.001$ & $1.90(1.22-2.96)$ & 0.005 \\
\hline$<2000$ grams & 690 & $53(7.7)$ & 1 (Ref) & & 1 (Ref) & \\
\hline \multicolumn{7}{|l|}{ Gestation age at birth } \\
\hline Preterm $(<37$ weeks $)$ & 201 & $33(16.4)$ & $1.81(1.19-2.75)$ & 0.006 & $1.47(1.07-2.28)$ & 0.043 \\
\hline Term ( $\geq 37$ weeks) & 684 & $64(9.4)$ & 1(Ref) & & 1 (Ref) & \\
\hline \multicolumn{7}{|c|}{ Feeding of babies within 28 days } \\
\hline Only breast milk & 509 & $50(11.0)$ & $1($ Ref $)$ & & & \\
\hline With additional food & 376 & $47(12.5)$ & $1.27(0.85-1.89)$ & 0.236 & & \\
\hline
\end{tabular}


On the other hand, it is quite incomparable and too much higher (almost 5-11-fold) than the risk of death among twins and LBW infants of a population-based study of developed countries, England and Wales. Rather it is comparable to the death rate of very low birth weight (VLBW) neonates of the same country $[25,26]$. This shows that the observed mortality rate among LBW neonates in rural Ethiopia is quite very high and may be one of the highest in the world [3, 20-23].

The main reason for such unacceptably high mortality among LBW neonates could be related to poor healthcare seeking behavior of mothers (caretakers) and/or families for neonatal and childhood health problems in such settings $[27,28]$. In addition, low availability and poor quality $[29,30]$ of child healthcare facilities in the area could further worsen the risk of death of LBW neonates.

Though we did not assess the causes of neonatal deaths using verbal autopsy, we could see that the leading predictors of death were related to maternal sociodemographic and obstetric characteristics that could be easily improved by providing a continuum of care to women during pregnancy, labor, immediate, and early neonatal periods [20]. Evidence suggests that three million babies and women could be saved each year by investing in quality care at the time of birth and special care for sick and small newborns; specifically care for low birth weight and sick newborns could avert $30 \%$ of neonatal deaths.

In this study, higher neonatal deaths occurred in the first week of life 42.3 (95\% CI: 33.0-51.5), compared to the second 25.8 (95\% CI: 17.5-35.1), third 24.7 (95\% CI: 16.533.0), and fourth weeks 7.2 (95\% CI: 2.1-13.4), which was consistent with previous findings [24-26]. The rate of death among LBW neonates was higher among mothers who had less than 4 ANC visits (83.9\%), had nonspontaneous assisted or caesarian delivery (54.6\%), and experienced illness during pregnancy $(59.8 \%)$. Similarly, neonates born with very low birth weight $(<2000 \mathrm{gm})$ carried a higher $(54.6 \%)$ risk of death compared to others (Table 3 ).

Neonates whose mothers attended formal education had a lower risk of death, which agreed with the studies done in Ethiopia [25] and Nigeria [16]. The reason may be that educated mothers have awareness of the advantages of maternal healthcare service utilization to both mother and their babies, and that has an effect on child survival in the postnatal period. Even though birth order and birth interval had statistical significance with neonatal death in previous studies $[16,26$, 28 ], these variables had no association with neonatal death in this study.

Similar to previous findings [24-29], the present study also revealed that the risk of neonatal death was higher among twins. However, after adjusting for other variables, the risk of death did not vary significantly by type of birth. This is mainly due to the fact that small size at birth and prematurity are major factors that increase the risk of neonatal death as premature, twining, and small size births are more likely to develop complications [16].

Inadequate or lack of ANC visits and occurrence of maternal illness were other maternal predictors for early neonatal deaths among LBW neonates in the study area. Several previous studies [26-29] have also reported lack of adequate and quality $\mathrm{ANC}$ visits that results in the inadequate monitoring of pregnancy, maternal, and neonatal complication during and after delivery, which was associated with increased risk of neonatal death. This suggests that special consideration needs to be given to maternal obstetric care during pregnancy.

LBW neonates born through assisted (instrumental or cesarean) delivery were also found to have two and four times added risk of dying compared to those born spontaneously. This could be related to elevated risk of infection and complications among nonspontaneous assisted deliveries as most are conducted after long-obstructed labor, usually referred from other facilities [25].

The study has several strengths that should be appreciated. Firstly, it is among the very few studies conducted to assess prevalence and risk factors of death among LBW neonates. Secondly, unlike the existing evidence often based on facility-based studies, the resent study employed community-based study design in an area where a birth registry is very uncommon. The study also made use of available local evidence to strengthen evidence generated. On the other hand, the study also has limitations that should be taken into consideration while interpreting the findings. We used our own operational definition for very low birth weight $(<2000 \mathrm{~g})$, unlike the conventional definition of a baby born $<1500 \mathrm{~g}$. This was made deliberately due to the fact that we have very few cases of the conventional definition leaving data analysis difficult or with poor meaningful interpretation. In addition, our study measured birth weight from health facility records which are not validated by concerned authorities for consistency and accuracy

\section{Conclusions}

In summary, the present study reported that the magnitude of neonatal mortality among LBW neonates was $11.0 \%$ (95\% CI: 17.5-22.8), which is one of the highest in the world and a fourfold of the national estimated neonatal mortality rate. The first week of life is the riskiest period for survival of LBW neonates. The risk of dying among LBW neonates is determined by both maternal sociodemographic and obstetric characteristics, and neonatal birth conditions. Maternal antenatal care attendance, mode of delivery, and experience of illnesses during pregnancy were among the maternal independent predictors of mortality among LBW neonates. Very low $(<2000 \mathrm{gm})$ birth weight and prematurity are neonatal independent predictors of death among LBW neonates in rural settings of Southern Ethiopia.

\section{Data Availability}

The authors confirm that all relevant data were included in the manuscript and the raw dataset can be obtained by email request to akine.eshete@yahoo.com.

\section{Ethical Approval}

Ethical clearance was obtained from Research and Ethics Committee of the College of Health Sciences and Medicine, Dilla University. 


\section{Disclosure}

The funder has no role in decisions regarding preparation or publication of the manuscript.

\section{Conflicts of Interest}

The authors declare that they have no conflicts of interest

\section{Authors' Contributions}

Akine Eshete and Abebe Alemu were involved in study conception, data processing, and analysis. Taddes Alemu Zerfu was responsible for data analysis and interpretation and preparation of the manuscript. All the authors read and approved the final manuscript.

\section{Acknowledgments}

We would like to acknowledge Dilla University for funding the study.

\section{References}

[1] UN IGME, Levels and Trends in Child Mortality: Estimates Developed by the UN Inter-Agency Group for Child Mortality Estimation, New York, NY, USA, 2011.

[2] D. You, L. Hug, S. Ejdemyr et al., "Global, regional, and national levels and trends in under-5 mortality between 1990 and 2015 , with scenario-based projections to 2030: a systematic analysis by the UN Inter-agency Group for child mortality estimation," Lancet, vol. 386, pp. 2275-2286, 1990.

[3] UNICEF, "The UN Inter-Agency Group for Child Mortality Estimation (IGME)," Levels and Trends in Child Mortality, 2015.

[4] Z. S. Lassi, B. A. Haider, and Z. A. Bhutta, "Community-based intervention packages for reducing maternal and neonatal morbidity and mortality and improving neonatal outcomes," Cochrane Database of Systematic Reviews (Online), vol. 3, Article ID CD007754, 2010.

[5] L. Liu, H. Johnson, S. Cousens, J. Perin, S. Scott, J. E. Lawn et al., "Global, regional and national causes of child mortality: an update systematic analysis for 2010 with time trends since 2000," The Lancet, vol. 379, no. 9832, pp. 2151-2161, 2012.

[6] N. Wakgari and E. Wencheko, "Original article Risk factors of neonatal mortality in Ethiopia," Ethiopian Journal of Health Development, vol. 2013, no. 10, 2011.

[7] Y. Mezgebu, A. Mossie, P. N. Rajesh, and G. Beyene, "Prevalence and severity of iodine deficiency disorder among children 612 years of age in shebe Senbo district, Jimma Zone, Southwest Ethiopia," Ethiopian Journal of Health Development, vol. 22, no. 3, pp. 196-204, 2012.

[8] B. Weldearegawi, Y. A. Melaku, S. F. Abera et al., "Infant mortality and causes of infant deaths in rural Ethiopia: a population-based cohort of 3684 births," BMC Public Health, vol. 15, no. 770, pp. 1-7, 2015.

[9] J. O. Akinyemi, E. A. Bamgboye, and O. Ayeni, "Trends in neonatal mortality in Nigeria and effects of bio-demographic and maternal characteristics," BMC Pediatrics, vol. 15, no. 36, pp. 1-12, 2015.
[10] M. C. McCormick, "The contribution of low birth weight to infant mortality and childhood morbidity," The New England Journal of Medicine, vol. 312, no. 2, pp. 82-90, 1985.

[11] WHO, Care of the preterm and_or low-birth-weight newborn, 2015.

[12] R. E. K. Stein, M. J. Siegel, and L. J. Bauman, "Are children of moderately low birth weight at increased risk for poor health? a new look at an old question," Pediatrics, vol. 118, no. 1, pp. 217223, 2006.

[13] WHO, Global Nutrition Targets 2025: Low Birth Weight Policy Brief (WHO/NMH/NHD/14.5), World Health Organization, Geneva, Switzerland, 2014.

[14] S. Muthayya, "Maternal nutrition \& low birth weight-what is really important?" Indian Journal of Medical Research, vol. 130, no. 5, pp. 600-608, 2009.

[15] H. Matsuo, "The health consequences of low birth weight: literature review and critique," Institut de Démographie, pp. 2223, 2003.

[16] R. J. Wood-Bradley, S. L. Henry, A. Vrselja, V. Newman, and J. A. Armitage, "Maternal dietary intake during pregnancy has longstanding consequences for the health of her offspring," Canadian Journal of Physiology and Pharmacology, vol. 91, no. 6, pp. 412-420, 2013.

[17] S. Iacobelli, P.-Y. Robillard, J.-B. Gouyon, T. C. Hulsey, G. Barau, and F. Bonsante, "Obstetric and neonatal outcomes of adolescent primiparous singleton pregnancies: A cohort study in the South of Reunion Island, Indian Ocean," The Journal of Maternal-Fetal and Neonatal Medicine, vol. 25, no. 12, pp. 25912596, 2012.

[18] J. M. Kothadia, T. M. O. Shea, D. Roberts, S. T. Auringer, R. Grey, and R. G. Dillard, Low Birth Weight Infants: Outcome of Study Participants at. 2014.

[19] C. G. Victora, J. H. Requejo, A. J. D. Barros et al., "Countdown to 2015: A decade of tracking progress for maternal, newborn, and child survival," The Lancet, vol. 387, no. 10032, pp. 2049-2059, 2016.

[20] Y. Berhan and A. Berhan, "Reasons for persistently high maternal and perinatal mortalities in Ethiopia: part II-Socioeconomic and cultural factors," Ethiopian Journal of Health Sciences, vol. 24, pp. 119-136, 2014.

[21] Y. Yaya, K. T. Eide, O. F. Norheim, and B. Lindtjørn, "Maternal and neonatal mortality in south-west ethiopia: estimates and socio-economic inequality," PLoS ONE, vol. 9, no. 4, Article ID e96294, 2014.

[22] CSAI, Ethiopia Demographic and Health Survey 2011, Central Statistical Agency and ICF International, Addis Ababa, Ethiopia, 2012.

[23] Y. Berhan and A. Berhan, "Perinatal mortality trends in Ethiopia," Ethiopian Journal of Health Sciences, vol. 24, pp. 2940, 2014.

[24] M. Aparecida, M. Gaiva, E. Fujimori, A. Paula, and S. Sato, "Neonatal mortality in infants with low birth weigh," Revista da Escola de Enfermagem da USP, vol. 48, no. 5, pp. 778-785, 2014.

[25] W. J. Watkins, S. J. Kotecha, and S. Kotecha, "All-cause mortality of low birthweight infants in infancy, childhood, and adolescence: population study of england and wales," PLoS Medicine, vol. 13, no. 5, pp. 1-19, 2016.

[26] S. V. Glinianaia, M. A. Obeysekera, S. Sturgiss, and R. Bell, "Stillbirth and neonatal mortality in monochorionic and dichorionic twins: a population-based study," Human Reproduction, vol. 26, no. 9, pp. 2549-2557, 2011. 
[27] Y. A. Gelaw, G. A. Biks, and K. A. Alene, "Effect of residence on mothers' health care seeking behavior for common childhood illness in Northwest Ethiopia: a community based comparative cross - sectional study," BMC Research Notes, vol. 7, no. 1, article 705,2014

[28] T. Kolola, T. Gezahegn, and M. Addisie, "Health care seeking behavior for common childhood illnesses in jeldu district, oromia regional state, Ethiopia," PLoS ONE, vol. 11, no. 10, 2016.

[29] W. Beyene, C. Jira, and M. Sudhakar, "Assessment of quality of health care in Jimma Zone, Southwest Ethiopia," The Ethiopian Journal of Health Development, vol. 21, no. 2, pp. 49-58, 2011.

[30] A. Getachew, J. Ricca, D. Cantor et al., "Quality of care for prevention and management of common maternal and newborn complications: a study of Ethiopia's hospitals," Baltimore, 2011. 


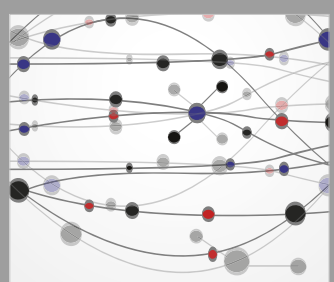

The Scientific World Journal
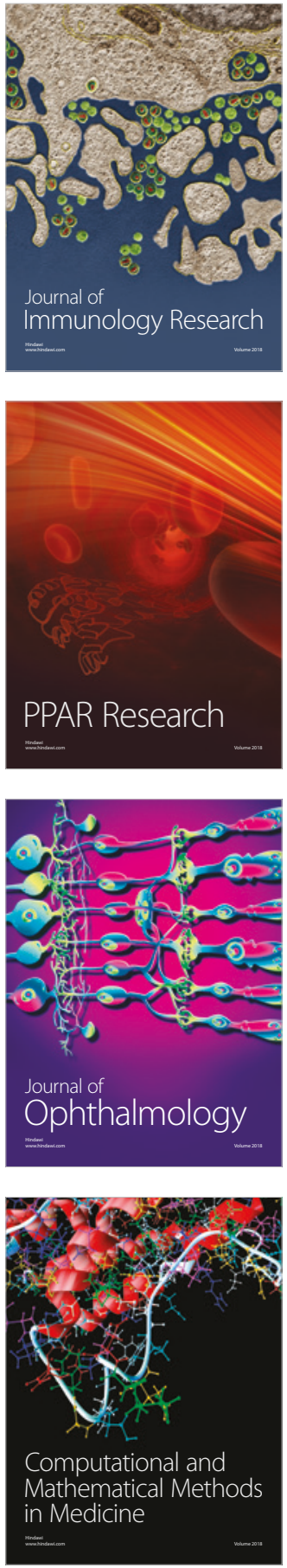

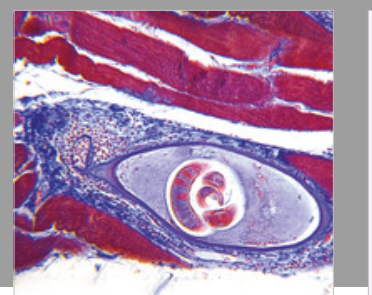

Gastroenterology Research and Practice

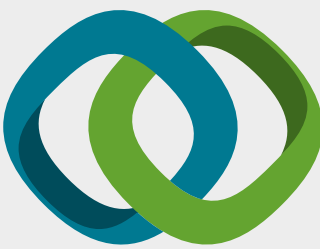

\section{Hindawi}

Submit your manuscripts at

www.hindawi.com
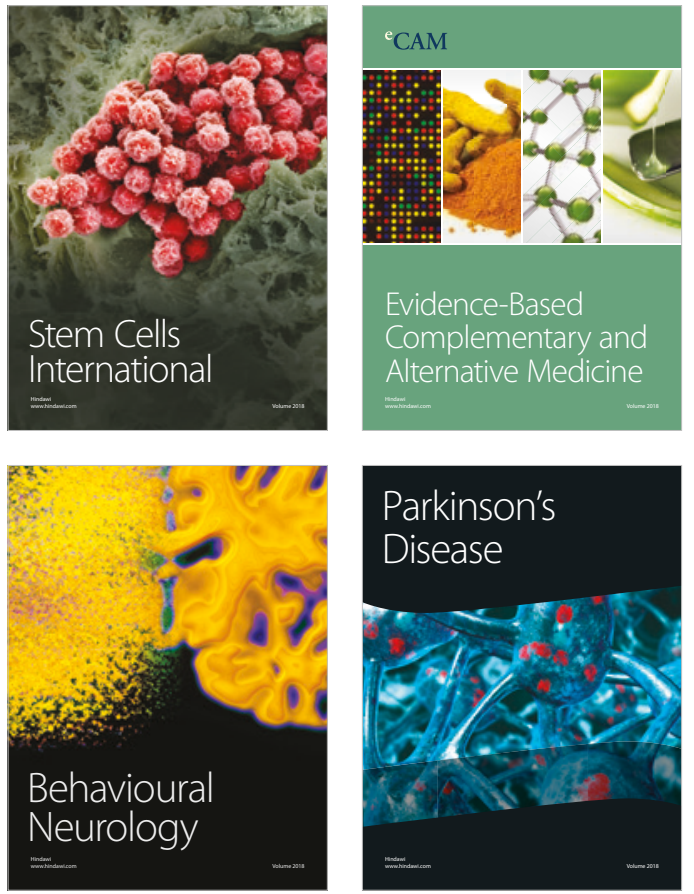

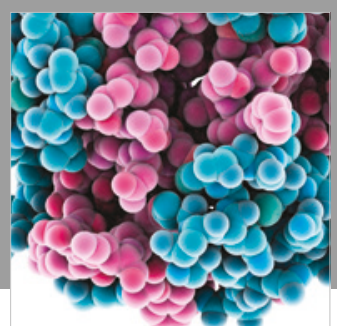

ournal of

Diabetes Research

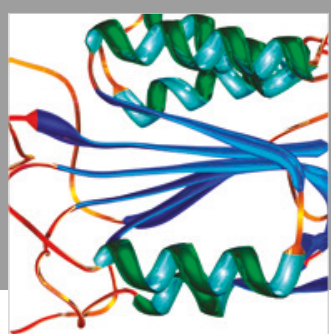

Disease Markers
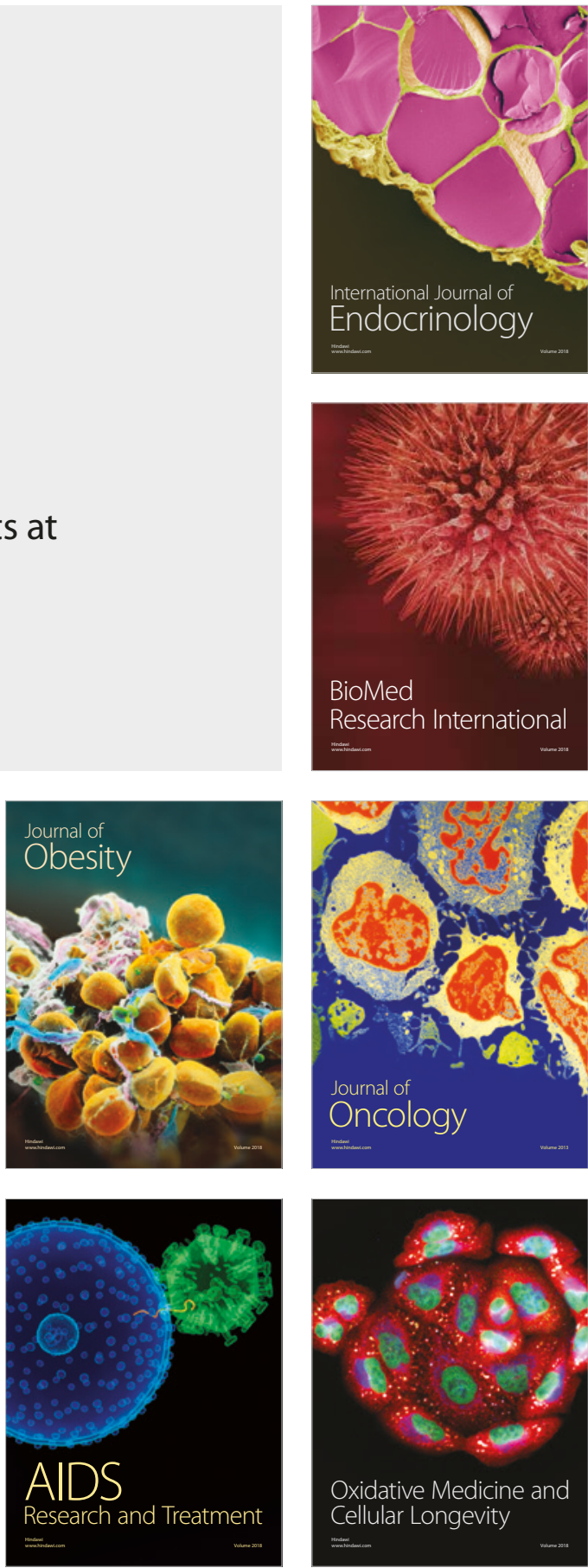